\title{
University Student Sample Is Unable to Accurately Assess Their Calorie Needs: Implications for Weight Management and Menu Labeling
}

\author{
Yu-Chieh Chen, Debra B. Reed, Natalia Velikova, Shu Wang
}

Department of Nutrition, Hospitality, and Retailing, College of Human Sciences, Texas Tech University, Lubbock, USA.

Email: debra.reed@ttu.edu

Received December $23^{\text {rd }}, 2011$; revised February $28^{\text {th }}, 2012$; accepted March $5^{\text {th }}, 2012$

\begin{abstract}
National surveys have shown that over $80 \%$ of adults do not know their recommended calorie levels. Lack of knowledge about calorie needs could be contributing to the high prevalence of obesity in the US. Young adulthood is a crucial period for the development of dietary behaviors that continue into later adulthood and influence the risk of obesity and chronic disease. This study examined university students' knowledge of their recommended calorie needs. Subjects (N $=153$ ) were students at Texas Tech University in Fall 2010. Students were given a survey to assess perceived daily calorie need (PDCN) and perceived daily calorie intake (PDCI). Their recommended daily calorie needs (RDCN) and actual calorie intakes (ACI) were determined using MyPyramid.gov. PDCN, PDCI, RDCN, and ACI were compared to determine students' ability to accurately estimate and consume recommended daily calorie levels. The range of their PDCN was $120 \mathrm{kcal}$ to $10,000 \mathrm{kcal}$. Only $19.7 \%$ of students estimated their RDCN accurately. There were significant differences between PDCN and RDCN ( $\mathrm{t}[152]=-3.223, \mathrm{P}=0.002)$; PDCI and $\mathrm{ACI}(\mathrm{t}[114]=3.246, \mathrm{P}=0.002)$; and $\mathrm{ACI}$ and $\mathrm{RDCN}(\mathrm{t}[114]=-5.6, \mathrm{P}=0.000)$. Nearly $40 \%$ of these university students were overweight. BMI had a significant effect $(\mathrm{P}=0.001)$ on students' estimation of their RDCN as students with underweight/normal BMI were more accurate. Nutrition education programs focused on calorie needs should be implemented with university students so they will be able to effectively use calorie information on food labels and menus for weight management.
\end{abstract}

Keywords: University Students; BMI; Knowledge of Calorie Needs

\section{Introduction}

The major nutrition concerns facing the US population are obesity and chronic diseases which are mainly influenced by diet [1,2]. Between 1988 and 2008, the prevalence of overweight and obese US adults increased from $58.9 \%$ to $73.7 \%$ of the population [3]. Knowledge of calorie needs and intake may be helpful in addressing the high prevalence of overweight and obesity in the US and the chronic diseases they influence.

The International Food Information Council (IFIC) Foundation conducts an annual survey with a sample of the US adult population, and the 2011 Survey showed that only $9 \%$ were able to accurately estimate their recommended daily calorie needs [4]. Several factors may be related to individuals' ability to accurately estimate their calorie needs. Carels and colleagues showed that adults in a weight loss program with a higher body mass index (BMI) were less accurate in caloric estimation of individual foods than those with a lower BMI at baseline [5]. However, in a study with university students, Carels and colleagues found that caloric estimations and ratings of foods' "healthiness" or "capacity to affect weight" in food did not differ as a function of either BMI status or gender [6]. African-American subjects ages 20 - 70 years who usually/often read nutrition labels and specific label nutrient information reported statistically significantly higher fruit and vegetable intakes and lower total fat, saturated fat, and fat-related behaviors, regardless of age, sex, and education [7]. In nationally representative data of US adults, nutrition knowledge and beliefs showed a significant and positive association with quality of dietary intake even when socioeconomic, lifestyle (smoking, exercise), and geographic factors were considered [8]. In a study of university students in Croatia, students with the highest nutrition knowledge were twelve times more likely to have a diet that met recommendations compared to students with the lowest level of knowledge [9]. While one study found that university campus meal plan subscription had little or no impact on student food consumption patterns or nutrient intake [10], a more 
recent study showed that students with meal plans have greater access and intake of most food groups compared to those who don't have meal plans [11]. A study of young adults found that living situation influences dietary patterns as those living with their parents or other non-campus sites appeared to have poorer dietary intake than those living on campus [12]. However, to the authors' knowledge, no previous study has examined the impact of gender, campus meal plan, reading food labels, BMI, and physical activity status on the ability of university students to estimate their calorie needs or intake. The purpose of this study with university students was to: 1) compare perceived daily calorie needs (PDCN) and recommended daily calorie needs (RDCN), compare reported actual calorie intake (ACI) and $\mathrm{RDCN}$, and compare perceived daily calorie intake (PDCI) and ACI; and 2) determine how other factors (such as gender, campus meal plan, reading food labels, BMI, and physical activity status) affect the students' ability to accurately estimate calorie needs and consume recommended calorie levels. It was hypothesized that there would be significant differences between PDCN and RDCN, ACI and RDCN, and PDCI and ACI. Additionally, it was hypothesized that BMI status would have a significant effect on students' ability to estimate $\mathrm{RDCN}$.

\section{Subjects and Methods}

\subsection{Subjects}

Undergraduate students enrolled in an introductory nutrition course for non-majors at Texas Tech University (TTU) in Fall 2010 were recruited to participate. This sample was out of 25,462 undergraduates enrolled in Fall 2010. This study was approved by the TTU Office of Research Services' Institutional Review Board.

\subsection{Survey}

On the first class day before class instruction had begun, a survey was administered to assess basic demographics, participation in the campus meal plan, exercise frequency and duration, frequency of reading food labels, perceived daily calorie needs, and perceived daily calorie intake. The survey was pretested with a separate class of 20 students in another department to ensure that wording was clear and responses were realistic.

\subsection{Calorie Estimation and Physical Measurements}

In the third week of the semester, students used MyPyramid.gov to record their food intake for 3 days (2 weekdays and 1 weekend day). Their ACI was then calculated automatically, and the mean calorie level of these 3 days of reported intake was then determined. Thus, PDCN and PDCI were asked on the survey before class instruction began, and ACI was determined at week 3 of the course.

Height and weight were measured in all students by a peer in the class using a stadiometer, and weights were measured in light clothing and bare feet on an electronic scale. Shoes, socks, hats and other personal items were removed for both height and weight measurements. Height and weight values were used to calculate their BMI status, expressed as weight (kilograms) $/$ height $^{2}$ (meters). BMI level was used to determine students who were in underweight (below 18.5), normal weight (18.5 24.9), overweight (25 - 29.9), and obese (above 30) categories. Additionally, students' age, gender, and exercise frequency and duration from the survey, and height and weight measurements were entered by individual students into MyPyramid.gov to determine their RDCN and ACI. PDCN, PDCI, RDCN, and ACI were compared to determine students' ability to estimate and consume recommended daily calorie levels. Based on the criteria in the IFIC Surveys [4], calorie estimations were considered accurate if they were $+/-100$ calories of the amount estimated by MyPyramid.

\subsection{Statistics Analysis}

Statistical analysis was conducted using SPSS (version 19.0, SPSS Inc, Chicago, IL), with a $P \leq 0.05$ considered statistically significant. Descriptive statistics were used to summarize variables. Paired t-tests were used to examine the difference between their RDCN and PDCN, RDCN and PDCI, RDCN and ACI, and PDCI and ACI. Analysis of variance was used to determine if gender, BMI category, campus meal plan, frequency of reading food labels, and exercise frequency and duration affect students' ability to estimate their daily calorie needs and calorie intakes. Independent samples chi-square tests were used to test for differences among categories. Data are presented in text, figures, and tables as means \pm standard deviations (SD).

\section{Results}

Characteristics of the sample of students $(\mathrm{N}=153)$ are presented in Table 1. The majority of students were female $(70 \%)$, did not have a campus meal plan $(67.3 \%)$, always/sometimes read food labels (77.2\%), and lived off campus $(85 \%)$. Approximately $40 \%$ of students were either overweight or obese. Most students (68.7\%) reported exercising $30-60 \mathrm{~min} /$ day, and over $50 \%$ exercised 2 times/week or 3 - 4 times/week.

The means \pm SD of PDCN, PDCI, RDCN, ACI are 
Table 1. Description of subjects in a study of university students $(\mathrm{N}=153)$.

\begin{tabular}{|c|c|c|c|}
\hline & Mean $\pm \mathrm{SD}$ & $\%$ & $\mathrm{n}$ \\
\hline Age (y) & $21.01 \pm 3.3$ & & 150 \\
\hline Height (in) & $66.37 \pm 4.17$ & & \\
\hline Weight (lb) & $156.86 \pm 39.87$ & & \\
\hline Gender Female & & 70.0 & 107 \\
\hline \multicolumn{4}{|l|}{ Campus Meal Plan } \\
\hline Yes & & 32.7 & 50 \\
\hline No & & 67.3 & 103 \\
\hline \multicolumn{4}{|l|}{ Read Food Label } \\
\hline Always & & 28.8 & 44 \\
\hline Sometimes & & 48.4 & 74 \\
\hline Rarely & & 15.7 & 24 \\
\hline Never & & 7.2 & 11 \\
\hline \multicolumn{4}{|l|}{ Residence } \\
\hline On-campus & & 15.0 & 23 \\
\hline Off-campus & & 85.0 & 130 \\
\hline BMI $\left(\mathrm{kg} / \mathrm{m}^{2}\right)$ & $25.01 \pm 6.05$ & & \\
\hline \multicolumn{4}{|l|}{ BMI 4 Categories } \\
\hline Underweight & & 2.6 & 4 \\
\hline Normal & & 58.2 & 89 \\
\hline Overweight & & 26.1 & 40 \\
\hline Obese & & 13.1 & 20 \\
\hline \multicolumn{4}{|l|}{ Exercise Duration $^{\mathrm{a}}$} \\
\hline$<30 \mathrm{~min} /$ day & & 5.2 & 8 \\
\hline $30-60 \mathrm{~min} /$ day & & 68.7 & 103 \\
\hline$>60 \mathrm{~min} /$ day & & 23.3 & 35 \\
\hline Do not exercise regularly & & 2.7 & 4 \\
\hline \multicolumn{4}{|l|}{ Exercise Frequency } \\
\hline Never exercise & & 2.0 & 3 \\
\hline Do not exercise regularly & & 11.1 & 17 \\
\hline$<1$ time/week & & 9.2 & 14 \\
\hline 2 times/week & & 20.9 & 32 \\
\hline 3 - 4 times/week & & 30.1 & 46 \\
\hline 5 - 6 times/week & & 15.0 & 23 \\
\hline Daily & & 10.5 & 16 \\
\hline
\end{tabular}

${ }^{\mathrm{a}} \mathrm{n}=150$. presented in Table 1. The range of values for PDCN and PDCI were $120 \mathrm{kcal}$ to $10,000 \mathrm{kcal}$, and $220 \mathrm{kcal}$ to $12,000 \mathrm{kcal}$, respectively (data not shown). Specifically, over $80 \%$ of students either under-estimated $(61.8 \%)$ or over-estimated (18.4\%) their RDCN (Figure 1). Students' knowledge of their daily calorie intake showed only $12.3 \%$ of students estimated their PDCI accurately based on their reported ACI (Figure 2). Approximately $58 \%$ of students overestimated their PDCI compared with their reported ACI (Figure 2). Students' ability to consume their recommended daily calorie level showed over $88 \%$ of students either over $(22.8 \%)$ or under (65.8\%) consumed their RDCN (Figure 3). The results

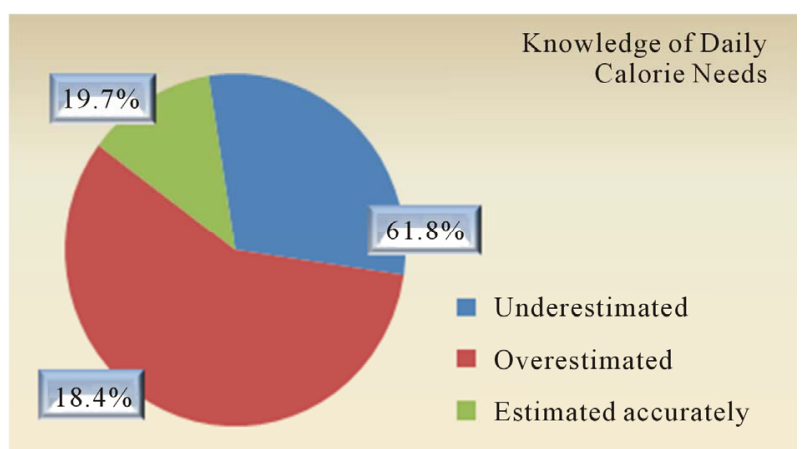

Figure 1. Knowledge of recommended daily calorie needs in university students $(n=152)$.

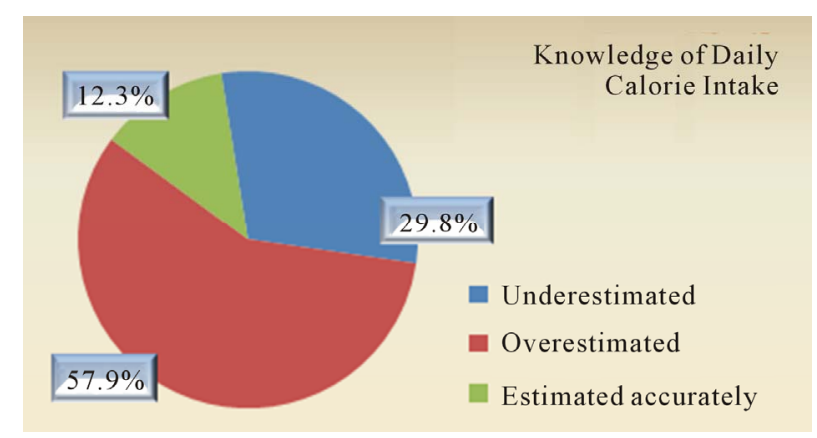

Figure 2. Knowledge of daily calorie intake in university students $(\mathbf{n}=114)$.

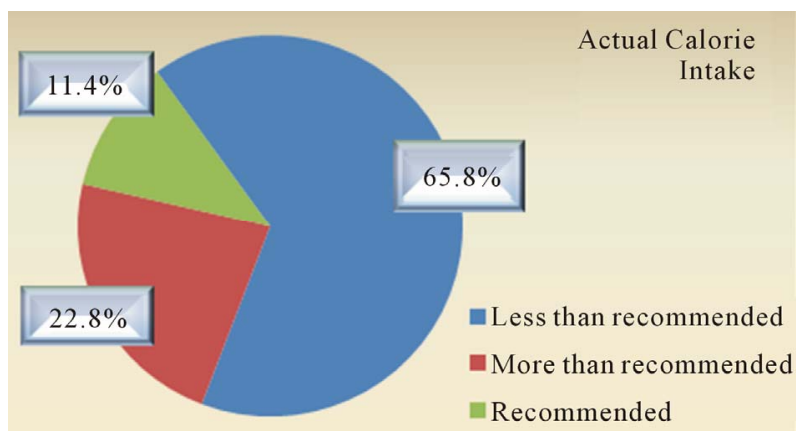

Figure 3. Reported daily calorie intake compared to recommended daily calorie intake in university students $(n=114)$. 
of differences between PDCN, PDCI, ACI, and RDCN showed that the students' estimated PDCN were significantly less than their calculated $\mathrm{RDCN}(\mathrm{t}=3.22, \mathrm{P}=$ $0.002)$; students' estimated PDCI were more than their reported ACI $(\mathrm{t}=3.25, \mathrm{P}=0.002)$; and students' calculated RDCN were significantly greater than their self reported ACI $(\mathrm{t}=5.60, \mathrm{P}=0.000)$ (Table 2).

Although the result was not significant, female students had better estimation of their RDCN than male students $(22.6 \%$ versus $13.0 \%$, respectively) $(\mathrm{P}=0.392)$ (Table 3). For the findings in Table 3 related to food labels, exercise frequency and duration, and BMI, the multiple categories were reclassified into two categories

Table 2. Differences between Recommended Daily Calorie Needs (RDCN), Perceived Daily Calorie Needs (PDCN), Perceived Daily Calorie Intake (PDCI), and Actual Calorie Intake (ACI) in university students $(n=153)$.

\begin{tabular}{|c|c|c|c|}
\hline Measures & \multicolumn{3}{|c|}{ Mean \pm SD } \\
\hline $\mathrm{PDCN}^{\mathrm{a}}$ & \multicolumn{3}{|c|}{$1989.43 \pm 966.38$} \\
\hline $\mathrm{PDCI}^{\mathrm{b}}$ & \multicolumn{3}{|c|}{$2340.61 \pm 1412.16$} \\
\hline $\mathrm{RDCN}^{\mathrm{b}}$ & \multicolumn{3}{|c|}{$2235.63 \pm 417$} \\
\hline $\mathrm{ACI}^{\mathrm{c}}$ & \multicolumn{3}{|c|}{$1859.61 \pm 755.16$} \\
\hline Measures & Mean difference & SD & $\mathrm{t}$ \\
\hline PDCN-RDCN & -248.06 & 948.93 & $-3.22^{*}$ \\
\hline PDCI-ACI & 381.53 & 1255.05 & $3.25^{*}$ \\
\hline ACI-RDCN & -349.82 & 667.01 & $-5.60^{* *}$ \\
\hline
\end{tabular}

${ }^{*} \mathrm{P}<0.01,{ }^{* *} \mathrm{P}<0.001 ;{ }^{\mathrm{a}} \mathrm{n}=152,{ }^{\mathrm{b}} \mathrm{n}=153,{ }^{\mathrm{c}} \mathrm{n}=114$.

Table 3. Perceived Daily Calorie Needs (PDCN) compared to Recommended Daily Calorie Needs (RDCN) by university student characteristics $(n=153)$.

\begin{tabular}{ccc}
\hline \multicolumn{2}{c}{ Characteristics } & $\begin{array}{c}\text { Accurate } \\
\text { Estimation }^{\mathrm{a}}(\%)\end{array}$ \\
\hline Gender & Females & 22.6 \\
Mead Food Label & Mlways/Sometimes & 13.0 \\
& Rarely/Never & 11.4 \\
Exercise Duration & $<30$ minutes/day & 41.7 \\
& $\geq 30$ minutes/day & 18.2 \\
Exercise Frequency & $\leq 2$ times/week & $27.7^{*}$ \\
& $\geq 3$ times/week & $12.9^{*}$ \\
BMI 2 Categories & Underweight/Normal & $28.3^{* *}$ \\
& Overweight/Obese & $6.7^{* *}$ \\
\hline
\end{tabular}

${ }^{*} \mathrm{P}<0.01,{ }^{* *} \mathrm{P}=0.001 ;{ }^{\mathrm{a}} \mathrm{PDCN}$ is \pm 100 calories of $\mathrm{RDCN}$. to increase subgroup size. Students who always/sometimes read food labels, more often accurately estimated their RDCN $(22.2 \%)$ than those who rarely/never read food labels (11.4\%), and those who always/sometimes read food labels $(70.3 \%)$ tended to consume fewer calories (based on their RDCN) than those who rarely/ never read food labels (47.8\%) (data not shown). However, these results related to reading food labels were not significant.

Students who exercised less than 30 min/day (41.7\%) were more accurate in estimating their RDCN than those who exercised more than $30 \mathrm{~min} /$ day (18.2), although this result was not significant $(\mathrm{P}=0.065)$. However, students' exercise frequency showed that those who exercised 3 or more times per week significantly estimated their RDCN less accurately (12.9\%), and more often overestimated their RDCN (25.9\%) compared to those who exercised 2 times or less per week $(27.7 \%$ and $9.2 \%$, respectively) $(\mathrm{P}=0.008)$ (Table 3 ).

Over $28 \%$ of the students in the underweight/normal weight group estimated their RDCN accurately compared to only $6.7 \%$ who were overweight/obese. The difference between the two BMI categories was significant $(\mathrm{P}=$ 0.001) (Table 3). Additionally, students with higher BMI were more likely to underestimate their $\mathrm{RDCN}$ than those with lower BMI (78.3\% vs. 51.1\%, respectively) (P $=0.001)$ (data not shown).

\section{Discussion}

The range of values for PDCN and PDCI (120 kcal to $10,000 \mathrm{kcal}$, and $220 \mathrm{kcal}$ to $12,000 \mathrm{kcal}$, respectively) showed a wide variation in students' perceptions of their calorie needs and reported intake. Although the $80 \%$ of students who either under-estimated or over-estimated their RDCN (Figure 1) is less than the $91 \%$ of US adults who did not know their recommended calorie levels as reported in the IFIC 2011 Food \& Health Survey [4], it is still an undesirably high lack of knowledge of calories. This lack of knowledge may contribute to students' inability to manage their weight effectively. According to students' knowledge of daily calorie intake, only $12.3 \%$ of students estimated their PDCI accurately (Figure 2). Two possibilities exist for the discrepancy between PDCI and ACI. First, students' knowledge of their calorie needs is lacking, and although we didn't assess their knowledge of the calorie content of food, this was possibly limited as well. Second, ACI may be biased as adult subjects frequently underreport food intake $[13,14]$. Since $88 \%$ of students did not consume their RDCN (Figure 3), students need education regarding their recommended calorie intake. Also, additional education or encouragement to accurately report their food intake may be needed when working with this population. 
Based on our results, the hypothesis that there would be significant differences between students' PDCN and their $\mathrm{RDCN}, \mathrm{PDCI}$ and their ACI, and ACI and their RDCN, were supported.

Although the following results were not statistically significant, they may have some practical value. The finding that a higher percent of female students were better at estimating their RDCN than male students was not consistent with a study of 101 undergraduate students that showed accuracy in caloric estimation did not differ as a function of gender [6]. Thus, more research is needed to evaluate the role of gender and knowledge of recommended calorie levels. The findings that students who always/sometimes read food labels estimated their RDCN more accurately than those who rarely/never read, and those who always/sometimes read food labels tended to consume fewer calories than those who rarely/ never read, are in the hypothesized direction. This suggests that reading food labels has potential for affecting knowledge related to management of calorie intake.

With the passage of H.R. 3590, the Patient Protection and Affordable Health Care Act, in March 2010, menu calorie labeling has become a national platform. Section 4205 of H.R. 3590 addresses menu labeling provisions on a federal level by mandating that restaurants and food vendors with more than 20 locations disclose calorie information for some items in their franchises and make other nutrient composition data available to consumers [15]. Our research has implications for this new menu labeling regulation in that if university students and other adults as per IFIC Surveys don't know their RDCN, then menu labeling with calorie information may not be very effective.

Results indicated there was no significant difference between students' exercise duration and their RDCN estimation. However, there was a significant difference between students' exercise frequency and RDCN estimation (Table 3) as we found that students who exercised more than 3 times per week tended to overestimate their RDCN compared to those who exercised less times per week. Our results might suggest that those students who exercised 3 or more times per week estimated their daily calories to be higher to account for perceived increased calorie needs of exercise, but this estimation was not accurate.

Our data showed that students in the underweight/ normal weight group were more likely to estimate their RDCN accurately than those who were overweight/obese which was consistent with our hypothesis. However, our results contrast with other studies $[6,16]$ in which accuracy in caloric estimation did not differ by weight status.
This study does present with some limitations. Height and weight were measured by peers in a lab class instead of by trained researchers. Students were instructed on proper methods to measure height and weight, but interobserver reliability was not determined. However, the IFIC studies $[4,17,18]$ and other national surveys, including the Behavioral Risk Factor Surveillance Study [19], rely on self-reported height and weight, which may be even less accurate. In addition, even though we had trained lab assistants teach students how to use MyPyramid to calculate their RDCN and ACI, students may not have completely followed the procedures. When students imported their food record into MyPyramid to calculate their ACI, students may not have included all of the food they had consumed, and may not have entered the correct portion size. Furthermore, we only collected food records for three days. Students might not have eaten typical foods on those selected days, causing their reported ACI to be under or over the true amount. If we had approximately a one week period for food intake record, their reported ACI might be more accurate. However, an extended number of food records may contribute to respondent burden which can reduce accuracy [20].

\section{Conclusion}

In this sample of university students, most students were unable to accurately estimate and consume their RDCN and unable to accurately estimate their ACI. Students with higher BMI were more likely to underestimate their RDCN, and students who exercised 3 or more times per week overestimated their daily calorie needs. Even though the accurate estimation of RDCN was slightly increased in those students who read food labels more often, the difference was not significant. Overall, our findings suggest that university students in this sample had limited knowledge about their RDCN and ACI. Nutrition education efforts related to accurate self-assessment of calorie needs and actual intake are needed as part of weight management strategies. Students can be directed to ChooseMyPlate.gov to determine their daily calorie needs based on age, gender, height, weight, and physical activity. Specifically, university students need to know their calorie needs in order to evaluate food labels and evaluate calorie information that will soon be required on restaurant menu items [15].

\section{REFERENCES}

[1] C. K. Roberts and R. J. Barnard, "Effects of Exercise and Diet on Chronic Disease," Journal of Applied Physiology, Vol. 98, No. 1, 2005, pp. 3-30. doi:10.1152/japplphysiol.00852.2004 
[2] J. Warren-Findlow and S. P. Hooker, "Disentangling the Risks Associated with Weight Status, Diet, and Physical Activity," Preventing Chronic Disease, Vol. 6, No. 4, 2009. http://www.cdc.gov/pcd/issues/2009/oct/08_0247.htm

[3] C. L. Ogden and M. D. Carroll, "Centers for Disease Control. Overweight and Obesity Trends among US Adults," 2010.

http://www.cdc.gov/NCHS/data/hestat/obesity_adult_07_ 08/obesity_adult_07_08.pdf

[4] International Food Information Council Foundation (IFIC), “2011 Food and Health Survey,” 2011. http://www.foodinsight.org/Content/3840/2011\%20IFIC $\%$ 20FDTN\%20Food\%20and\%20Health\%20Survey.pdf

[5] R. A. Carels, J. Harper and K. K. Konrad, "Qualitative Perceptions and Caloric Estimations of Health and Unhealthy Foods in Behavioral Weight Loss Participants," Appetite, Vol. 46, No. 2, 2006, pp. 199-206. doi:10.1016/j.appet.2005.12.002

[6] R. A. Carels, K. Konrad and J. Harper, "Individual Differences in Food Perceptions and Calorie Estimation: An Examination of Dieting Status, Weight, and Gender," Appetite, Vol. 49, No. 2, 2007, pp. 450-458. doi:10.1016/j.appet.2007.02.009

[7] J. A. Satia, J. A. Galanko and M. L. Neuhouser, "Food Nutrition Label Use Is Associated with Demographic, Behavioral, and Psychosocial Factors and Dietary Intake among African Americans in North Carolina," Journal of the American Dietetic Association, Vol. 105, No. 3, 2005, pp. 392-402. doi:10.1016/j.jada.2004.12.006

[8] M. A. Beydoun, L. M. Powell and Y. Wang, "Reduced Away-From-Home Food Expenditure and Better Nutrition Knowledge and Belief Can Improve Quality of Dietary Intake among US Adults," Public Health Nutrition, Vol. 12, No. 3, 2008, pp. 369-381.

[9] G. Kresic, G. K. Jovanovic, S. P. Zezelj, O. Cvijanovic and G. Ivezic, "The Effect of Nutrition Knowledge on Dietary Intake among Croatian University Students," Collegium Antropologicum, Vol. 33, No. 4, 2009, pp. 10471056.

[10] J. F. Hernon, J. D. Skinner, F. E. Andrews and M. P. Penfield, "Nutrient Intakes and Foods Selected by College Students: Comparisons among Subgroups Divided by Energy Intake," Journal of the American Dietetic Association, Vol. 86, 1986, pp. 217-221.

[11] L. B. Brown, R. K. Dresen and D. L. Eggett, "College Students Can Benefit by Participating in a Prepaid Meal
Plan," Journal of the American Dietetic Association, Vol. 105, No. 3, 2005, pp. 445-448. doi:10.1016/i.jada.2004.12.030

[12] M. N. Laska, N. I. Larson, D. Neumark-Sztainer and M. Story, "Dietary Patterns and Home Food Availability during Emerging Adulthood: Do They Differ by Living Situation?" Public Health Nutrition, Vol. 13, No. 2, 2010 , pp. 222-228. doi:10.1017/S1368980009990760

[13] V. A. Vance, S. J. Woodruff, L. J. McCargar, J. Husted and R. M. Hanning, "Self-Reported Dietary Energy Intake of Normal Weight, Overweight and Obese Adolescents," Public Health Nutrition, Vol. 12, No. 2, 2007, pp. 222-227. doi:10.1017/S1368980008003108

[14] L. Johansson, K. Solvoll, G. A. Bjørneboe and C. A. Drevon, "Under- and Overreporting of Energy Intake Related to Weight Status and Lifestyle in a Nationwide Sample," The American Journal of Clinical Nutrition, Vol. 68, 1998, pp. 266-74.

[15] K. Stein, "A National Approach to Restaurant Menu Labeling: The Patient Protection and Affordable Health Care Act, Section 4205," Journal of the American Dietetic Association, Vol. 110, No. 9, 2010, pp. 1280-1289. doi:10.1016/j.jada.2010.07.017

[16] B. Wansink and P. Chandon, "Meal Size, Not Body Size, Explains Errors in Estimating the Calorie Content of Meals," Annals of Internal Medicine, Vol. 145, 2006, pp. 326-332.

[17] International Food Information Council Foundation (IFIC), "2010 Food and Health Survey," 2010. http://www.foodinsight.org/Content/3651/2010FinalFullR eport.pdf

[18] International Food Information Council Foundation (IFIC), "2009 Food and Health Survey," 2009.

http://www.foodinsight.org/Resources/Detail.aspx?topic= 2009_Food_Health_Survey_Consumer_Attitudes_toward _Food_Nutrition_and_Health

[19] M. Ezzati, H. Martin, S. Skjold, S. V. Hoorn and C. J. Murray, "Trends in National and State-Level Obesity in the USA after Correction for Self-Report Bias: Analysis of Health Surveys," Journal of the Royal Society of Medicine, Vol. 99, No. 5, 2006, pp. 250-257. doi:10.1258/jrsm.99.5.250

[20] Y. J. Yang, M. K. Kim, S. H. Hwang, Y. Ahn, J. E. Shim and D. H. Kim, "Relative Validities of 3-Day Food Records and the Food Frequency Questionnaire" Nutrition Research and Practice, Vol. 4, No. 2, 2010, pp. 142-148. 